Novartis, Pfizer, Roche, and UCB., CODRINA ANCUTA Speakers bureau: AbbVie, Eli Lilly, Ewopharma, MSD, Novartis, Pfizer, Roche, and UCB., Consultant of: AbbVie, Eli Lilly, Ewopharma, MSD, Novartis, Pfizer, Roche, and UCB. Ivan Lagunes-Galindo Employee of: AbbVie employee and may own stocks or options, Maria DeLaVega: None declared, Umut Kalyoncu Speakers bureau: AbbVie, Amgen, Eli Lilly, Janssen, Novartis, Pfizer, Roche, and UCB., Consultant of: AbbVie, Amgen, Eli Lilly, Janssen, Novartis, Pfizer, Roche, and UCB., Orsolya Nagy Employee of: AbbVie employee and may own stocks or options Atsushi Kawakami Speakers bureau: AbbVie, Actelion, Asahi Kasei, Astellas Boehringer Ingelheim, Celltrion, Chugai, Daiichi Sankyo, Eisai, Eli Lilly, GSK, Janssen, Kowa, MedPeer, Mitsubishi Tanabe, Novartis, ONO, Pfizer, Taisho, and Takeda, Grant/research support from: AbbVie, Actelion, Asahi Kasei, Astellas, AYUMI, Boehringer Ingelheim, Bristol-Myers Squibb, Celltrion, Chugai, Daiichi Sankyo, Eisai, Eli Lilly, Kyowa Hakko Kirin, MSD, Neopharma, Novartis, ONO, Sanofi, Taisho, Takeda Science Foundation, and Teijin. DOI: 10.1136/annrheumdis-2021-eular.842

\section{POS0513 ABATACEPT IN MONOTHERAPY VERSUS COMBINED IN INTERSTITIAL LUNG DISEASE OF RHEUMATOID ARTHRITIS. MULTICENTER STUDY OF 263 CAUCASIAN PATIENTS}

C. Fernández-Díaz ${ }^{1}$, B. Atienza-Mateo ${ }^{1}$, S. Castañeda ${ }^{2}$, R. Melero ${ }^{3}$, F. OrtizSanjuán $^{4}$, I. Casafont-Solé ${ }^{5}$, J. Loricera ${ }^{1}$, S. C. Rodriguez-García ${ }^{6}$, I. FerrazAmaro $^{7}$, M. A. González-Gay ${ }^{1}$, R. Blanco on behalf of Spanish Collaborative Group of Interstitial Lung Disease Associated to Rheumatoid Arthritis Members of the Spanish Collaborative Group of Interstitial Lung Disease Associated to Rheumatoid Arthritis: Clara Aguilera-Cros (H.U. Virgen del Rocío, Sevilla), Ignacio Villa (H. Sierrallana, Torrelavega), Enrique Raya-Alvarez (H.U. San Cecilio, Granada), Clara Ojeda-García (H.U. Virgen Macarena, Sevilla), María G. Bonilla Hernán (H.U. La Paz, Madrid), Ana M. López-Robles (H.U. Vall d' Hebron, Barcelona), Luis Arboleya-Rodríguez (H.U. Central de Asturias, Asturias), Javier Narváez García (H.U. Bellvitge, Barcelona), Evelin C. Cervantes Pérez (H.U. de Santiago, Santiago de Compostela, A Coruña), OlgaMaiz-Alonso (H.U. Donostia, Gipuzkoa), María N. Alvarez-Rivas (H.U. Luca Augusti, Lugo), Iván Cabezas-Rodríguez (H.U. Río Hortega, Valladolid), Eva Salgado-Pérez (C.H.U. Ourense, Ourense), Cristina Hidalgo-Calleja (H.U. de Salamanca, Salamanca), Sabela Fernández-Aguado (H.U. Cabueñes, Asturias), Jesús C. Fernández-López (C.H.U. A Coruña), Alejandro Olivé, Samantha Rodríguez-Muguruza (H.U. GermansTrias i Pujol, Barcelona), Raquel Almodóvar-González (H.U. Fundación Alcorcón, Madrid), Carmen Carrasco-Cubero (C.H.U. Infanta Cristina, Badajoz), Antonio Juan-Mas (H. Son Llàtzer, Palma de Mallorca), Raúl Castellanos-Moreira (H.U. Clinic. Barcelona), Iñigo Hernández Rodríguez (C.H.U. de Vigo, Vigo), Neus QuillisMarti (H. Vinalopo Elche), José A. Bernal-Vidal (H. Marina Baixa, Villajoyosa), Angel García-Aparicio (H. Virgen de la salud, Toledo), Sonia Castro-Oreiro (H.U. Joan XXIII, Tarragona), Julia Fernández-Melón (H. Son Espases, Palma de Mallorca), Paloma Vela Casasempere(H. U. Alicante, Alicante), María C. Fito, Carmen González-Montagut (C.U. Navarra, Navarra), Manuel Rodríguez-Gómez (C.H.U. Ourense, Ourense), Trinidad Pérez-Sandoval, Miriam Retuerto-Guerrero (H.U. León), Deseada Palma-Sánchez (H. Rafael Mendez, Lorca), José L. Andreu (H. U. Puerta del Hierro), Patricia CarreiraDelgado (H. 12 de Octubre, Madrid), Lorena Expósito-Pérez (H.U. de Canarias, Tenerife), Juan RD Jiménez- de Aberásturi, Ana Ruibal-Escribano (H.U. Txagorritxu, Araba), Ana Urruticoechea-Arana (H. Can Misses, Ibiza), Rosa Expósito-Molinero (H. Laredo, Laredo), Rubén López Sánchez (H. Negrín Las Palmas), Manuel J.Moreno-Ramos (H. Virgen de la Arrixaca, Murcia), Isabel Serrano-García (H. Puerta del Mar Cadiz), Blanca García-Magallón (H. San Jorge Huesca), José María Andreu Ubero (H. Virgen de las Nieves Granada), Natalia Mena-Vázquez (H.R.U Málaga), Iván Castellvi-Barranco (H.U. De la Santa Creu i Sant Pau, Barcelona), Carmen González-Montagut (H. U. Valladolid, Valladolid), Juan Blanco-Madrigal (H. Basurto, Bilbao), Pilar Morales-Garrido (H.U. San Cecilio, Granada), Cilia Peralta-Ginés (H. Lozano Blesa, Zaragoza), Mireia López-Corbeto (H.U. Vall d’Hebron, Barcelona), Sergio Ordóñez-Palau (H. Lleida, Lleida), Andrea García-Valle (H. U Palencia), Susana Romero-Yuste (H.U. Pontevedra, Pontevedra).. ${ }^{1}$ Marqués de Valdecilla University Hospital, Rheumatology, Santander, Spain; ${ }^{2}$ Hospital de La Princesa, Rheumatology, Madrid, Spain; ${ }^{3}$ Complejo Hospitalario Universitario de VIgo, Rheumatology, Vigo, Spain; ${ }^{4}$ Hospital La Fe, Rheumatology, Valencia, Spain; ${ }^{5}$ Hospital Germans Trias i Pujol, Rheumatology, Badalona, Spain; ${ }^{6}$ Hospital Clínic, Rheumatology, Barcelona, Spain ${ }^{7}$ Hospital Universitario de Canarias, Rheumatology, San Cristóbal de La Laguna, Spain
Background: Interstitial lung disease (ILD) is a severe complication of RA. Abatacept (ABA) have demonstrated efficacy in RA-ILD [1,2], although combined treatment with MTX or others DMARDs remain controversial.

Objectives: To assess the efficacy and safety of $A B A$ in monotherapy ( $\left.A B A_{\text {MONo }}\right)$ versus combined-ABA, ABA plus MTX(ABA $\left.A_{M T X}\right)$ or ABA plus other non-MTX DMARDs (ABA NON-MTX $_{\text {, }}$ ), in RA-ILD.

Methods: Observational multicenter study of RA-ILD caucasian patients treated

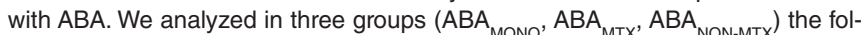
lowing outcomes: a) Dyspnea, b) FVC and DLCO, c) HRCT, d) DAS28-ESR, e) corticosteroid-sparing effect. Differences between basal and final follow-up were evaluated. Multivariable linear regression was used between the three groups. Results: We studied 263 RA-ILD patients (mean age 64.6 \pm 10 years) [ABA $(n=111), A^{-1 A_{M T X}}(n=46)$ and $\left.A_{B A} A_{\text {NON-MTX }}(n=106)\right]$. At baseline, $A B A_{\text {MONO }}$ patients were older ( $67 \pm 10$ years) and took higher prednisone dose (10 [IQR 5-15] mg/ day). There was no statistically significant differences in sex, seropositivity, ILD patterns, FVC, DLCO or disease duration. In all groups, most patients experienced stabilization or improvement in FVC, DLCO, dyspnea, HRCT as well as improvement in DAS28-ESR. A statistically significant difference between basal and final follow-up was only found in corticosteroid-sparing effect in $\mathrm{ABA}_{\mathrm{MTX}}$ or $\mathrm{ABA}_{\mathrm{NON}-\mathrm{MTX}}$ (Figure 1). However, in the multivariable analysis, there were no differences in any outcome between the three groups(Table 1).
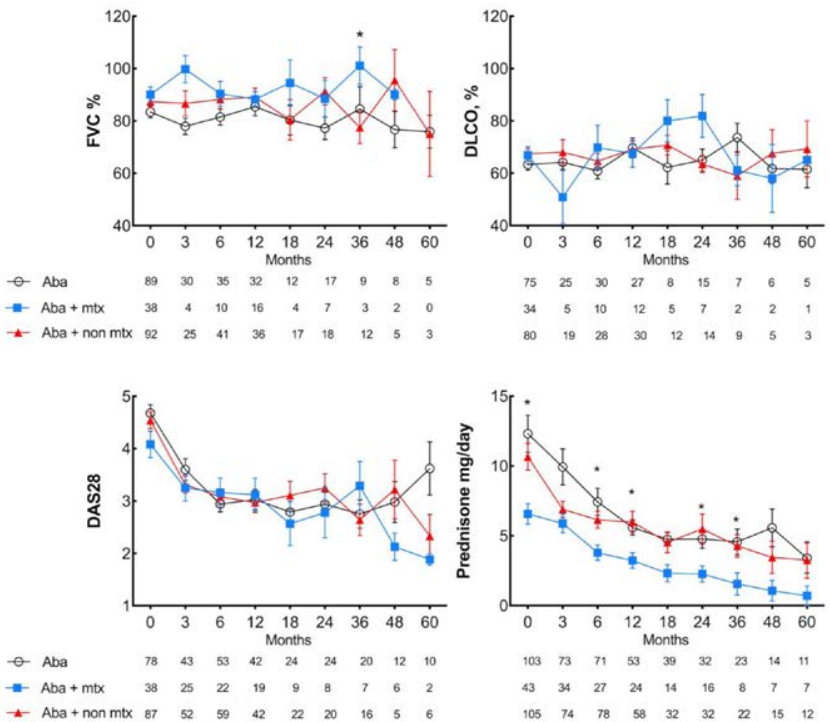

$-A b a+m t x$

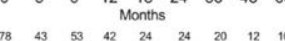

$\begin{array}{lllllll}105 & 74 & 78 & 58 & 32 & 3 & 0\end{array}$

Figure 1.

Conclusion: In caucasian individuals with RA-ILD, ABA ${ }_{\mathrm{MONO}}$ or $\mathrm{ABA}_{\mathrm{MTX}}$ or ABANON-MTX seems to be equally effective and safe. However, a corticosteroid-sparing effect is only observed in combined-ABA

\section{REFERENCES:}

[1] Fernández-Díaz C, et al. Abatacept in patients with rheumatoid arthritis and interstitial lung disease: A national multicenter study of 63 patients. Semin Arthritis Rheum. 2018 Aug;48(1):22-27. doi: 10.1016/j.semarthrit.2017.12.012.

[2] Fernández-Díaz C, et al. Abatacept in interstitial lung disease associated with rheumatoid arthritis: national multicenter study of 263 patients. Rheumatology (Oxford). 2020 Dec 1;59(12):3906-3916. doi: 10.1093/rheumatology/ keaa621.

Acknowledgements: Spanish Collaborative Group of Interstitial Lung Disease Associated to Rheumatoid Arthritis

Disclosure of Interests: Carlos Fernández-Díaz Speakers bureau: Roche, bristol myers squibb, Belén Atienza-Mateo: None declared, Santos Castañeda: None declared, Rafael Melero: None declared, Francisco Ortiz-Sanjuán: None declared, Ivette Casafont-Solé: None declared, J. Loricera: None declared, Sebastián C Rodriguez-García: None declared, Iván Ferraz-Amaro: None declared, Miguel A González-Gay: None declared, Ricardo Blanco Speakers bureau: bristol myers squibb

DOI: 10.1136/annrheumdis-2021-eular.892 
Table 1. Effect in FVC, DLCO, dyspnea (mMRC) and HRCT pulmonary scan after abatacept.

\begin{tabular}{|c|c|c|c|c|c|c|c|c|c|c|c|}
\hline & $\begin{array}{c}\text { ABA }_{\text {MONO }} \\
\mathrm{N}=111\end{array}$ & & $\begin{array}{c}\mathrm{ABA}_{\mathrm{MTx}} \\
\mathrm{N}=46\end{array}$ & & $\begin{array}{c}\text { ABA }_{\text {NON-MTX }} \\
N=106\end{array}$ & & & $\begin{array}{l}\text { ABA }_{\text {MTX }} \text { vs } \\
\text { ABA }_{\text {MONO }}\end{array}$ & & $\begin{array}{c}\text { ABA }_{\text {NON-MTX }} \text { vs } \\
\text { ABA }_{\text {MONO }}\end{array}$ & \\
\hline & & $\mathrm{p}$ & & $\mathrm{p}$ & & $\mathrm{p}$ & $\mathrm{p}^{*}$ & Unadjusted & Adjusted $^{\star \star}$ & Unadjusted & Adjusted** \\
\hline $\begin{array}{l}\text { Follow-up, median [IQR] months } \\
\text { Differences between basal and }\end{array}$ & $\begin{array}{l}12[6-36] \\
\text { Il follow-up }\end{array}$ & & $12[6-36]$ & & $18[12-36]$ & & 0.40 & & 0.67 & & 0.17 \\
\hline FVC, \% & $-0.5(-2.5,1.5)$ & 0.64 & $1.2(-0.6,3.1)$ & 0.17 & $-1.2(-2.9,0.5)$ & 0.17 & 0.33 & 0.30 & 0.39 & 0.59 & 0.90 \\
\hline $\begin{array}{l}\text { DLCO, \% } \\
\text { mMRC, n (\%) }\end{array}$ & $1.8(-0.7,4.34)$ & 0.16 & $0.5(-3.8,4.8)$ & 0.82 & $-1.5(-4.1,1.1)$ & 0.26 & 0.20 & 0.58 & 0.80 & 0.07 & 0.32 \\
\hline $\begin{array}{l}\text { Worsening } \\
\text { Stable or improving } \\
\text { HRCT pulmonary scan, n (\%) }\end{array}$ & $\begin{array}{c}5(5) \\
93(95)\end{array}$ & & $\begin{array}{c}3(8) \\
36(92)\end{array}$ & & $\begin{array}{c}5(5) \\
87(95)\end{array}$ & & 0.83 & & 0.47 & & 0.99 \\
\hline $\begin{array}{l}\text { Worsening } \\
\text { Stable or improving }\end{array}$ & $\begin{array}{l}13(28) \\
34(72)\end{array}$ & & $\begin{array}{c}2(11) \\
19(89)\end{array}$ & & $\begin{array}{l}15(25) \\
44(75)\end{array}$ & & 0.24 & & 0.10 & & 0.78 \\
\hline $\begin{array}{l}\text { DAS28-ESR } \\
\text { Prednisone, mg/day }\end{array}$ & $\begin{array}{l}-1.5(-1.9,-1.0) \\
-3.8(-8.3,0.8)\end{array}$ & $\begin{array}{c}0.000 \\
0.10\end{array}$ & $\begin{array}{l}-1.2(-1.8,-0.6) \\
-2.7(-4.6,-0.8)\end{array}$ & $\begin{array}{l}0.000 \\
0.006\end{array}$ & $\begin{array}{l}-1.5(-1.8,-1.2) \\
-4.8(-6.3,-3.4)\end{array}$ & $\begin{array}{l}0.000 \\
0.000\end{array}$ & $\begin{array}{l}0.74 \\
0.69\end{array}$ & $\begin{array}{l}0.58 \\
0.67\end{array}$ & & $\begin{array}{l}0.92 \\
0.65\end{array}$ & \\
\hline
\end{tabular}

\section{POS0514 IMPORTANCE OF BODY MASS MEASUREMENT AND THE GRIP STRENGTH TEST TO PREDICT FALLS IN PATIENTS WITH RHEUMATOID ARTHRITIS}

M. Tada ${ }^{1}$, Y. Yamada ${ }^{2}$, K. Mandai ${ }^{3}$, N. Hidaka'. ' Osaka City General Hospital, Orthopaedic Surgery, Osaka, Japan; ${ }^{2}$ Osaka City University Medical School, Orthopaedic Surgery, Osaka, Japan; ${ }^{3}$ Osaka Saiseikai Nakatsu Hospital, Orthopaedic Surgery, Osaka, Japan

Background: We previously reported that the prevalence of sarcopenia was $28 \%$ in patients with rheumatoid arthritis (RA) in a cohort study ${ }^{1}$. RA patients have a high risk of falls and fractures ${ }^{2}$. However, the predictors of falls and fractures in RA patients are not known.

Objectives: Whether evaluation of muscle mass and function at baseline could predict falls and fractures during four-year follow-up was investigated.

Methods: The four-year follow-up data from a prospective, observational study (CHIKARA study: Correlation researcH of sarcopenla, sKeletal muscle and disease Activity in Rheumatoid Arthritis) were used. Muscle mass was measured by a body impedance analyzer, and leg muscle mass was calculated. The leg muscle score (max: 100, min: 0) reflected the ratio of leg muscle mass to overall weight. Grip strength as an indicator of muscle function was evaluated using a digital, hand-held, isokinetic dynamometer. The correlations between muscle mass or function and falls or fractures were analyzed by survival rates and Cox hazard ratios. Leg muscle mass and grip strength were investigated by receiver operating characteristic (ROC) curve analysis for correlations with falls or fractures.

Results: A total of 100 RA patients (female: $78 \%$, mean age: 66.1 years) were enrolled; 35 patients had falls, and 19 patients had fractures during the four-year follow-up. The leg muscle score, grip strength, age, and fractures at baseline were significantly correlated with falls. The cut-off values of the leg muscle score and grip strength were calculated to be 84.5 points (sensitivity: 0.79 , specificity: 0.43 ) and $15.9 \mathrm{~kg}$ (sensitivity: 0.56 , specificity: 0.70 ), respectively, by ROC curve analysis. The patients were divided into four groups by their leg muscle scores and grip strength; the numbers of falls and fractures are shown in Table 1 for each group. The fall-free survival rate was significantly lower in the group with low leg muscle score and low grip strength (35.3\%) than in the other groups ( $P=0.002)$ (Figure 1). The hazard ratio for the both low group was significantly increased, 3.6 -fold $(95 \% \mathrm{Cl}: 1.1-11.5)$, compared to that in the both high group.

Table 1. Numbers of falls and fractures by category of leg muscle score and grip strength

$L G+G S+(n=34) L G-G S+(n=12) L G+G S-(n=37) L G-G S-(n=17) P$ value $^{*}$

\begin{tabular}{llllll} 
Falls, N & 6 & 5 & 15 & 11 & 0.010 \\
Fractures, N & 3 & 4 & 6 & 6 & 0.072 \\
\hline
\end{tabular}

LG+: leg muscle score $>84.5$ points, GS+: grip strength $>15.9 \mathrm{~kg}$, LG-: leg muscle score $\leq 84.5$ points, GS+: grip strength $\leq 15.9 \mathrm{~kg}{ }^{*}$ : compared in four groups by Kruskal-Walls test.

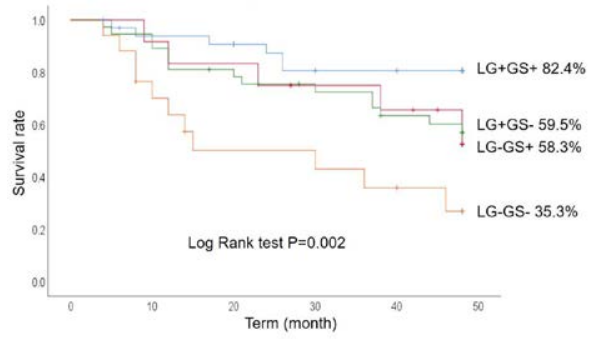

Figure 1. Fall-free survival rate in the four groups
Conclusion: RA patients with both low leg muscle score and low grip strength at baseline were at high risk for falls during the four-year follow-up period. Evaluation of muscle mass and function can predict falls in RA patients.

REFERENCES:

[1] Tada, M., Yamada, Y., Mandai, K. \& Hidaka, N. Matrix metalloprotease 3 is associated with sarcopenia in rheumatoid arthritis - results from the $\mathrm{CHI}$ KARA study. Int J Rheum Dis 21, 1962-1969, doi:10.1111/1756-185X.13335 (2018).

[2] van Staa, T. P., Geusens, P., Bijlsma, J. W., Leufkens, H. G. \& Cooper, C. Clinical assessment of the long-term risk of fracture in patients with rheumatoid arthritis. Arthritis Rheum 54, 3104-3112, doi:10.1002/art.22117 (2006).

Disclosure of Interests: None declared

DOI: 10.1136/annrheumdis-2021-eular.940

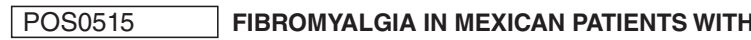 RHEUMATOID ARTHRITIS}

L. D. Fajardo Hermosillo ${ }^{1} .{ }^{1}$ Instituto Mexicano del Seguro Social, Centro Médico Nacional de Occidente, Rheumatology, Guadalajara, Mexico

Background: Rheumatoid Arthritis (RA) is a disabling chronic inflammatory disease that shows an unpredictable and severe clinical course [1]. Global assessment, functional status and disease activity of patients with RA can be influenced also by non-inflammatory factors as concomitant presence of fibromyalgia (FM) $[1,2]$. FM occur up to $20 \%$ in RA patients, who present chronic widespread pain, fatigue and cognitive symptoms that impacts achieving a complete disease remission, having more comorbidities, bearing a higher medical cost and finally exhibiting a worse quality of life $[1,3,4]$. Range of manifestations of FM varies according ethnical and cultural differences between patients [1]. Here is presented the impact of fibromyalgia in Mexican patients with RA.

Objectives: To determinate the frequency and factors associated to fibromyalgia in Mexican RA patients.

Methods: 624 patients with RA that fulfilled ACR/EULAR 2010 criteria ( $\geq 18$ years) from a Mexican population recruited from 2012 to 2020 were examined. Patients with or without presence of FM diagnosed by ACR 2010/2011 criteria were included. Demographic factors, clinical features, disease activity measured using DAS28 (Disease Activity Score 28-joint counts), functional status evaluated by HAQ (Health Assessment Questionnaire), comorbidities and pharmacologic treatments were explored for RA patients with and without FM. Charlson's comorbidity index $(\mathrm{CCl})$ was used to analyze comorbidities. Chi-square, Student's-t, U Mann-Whitney tests were performed by univariate analysis and logistic regression was executed by multivariate analysis adjusted for age and gender. Statistical tests were conducted at $5 \%$ level of significance. Results: Of 624 patients with RA $88.8 \%$ were women. The mean age [standard deviation (SD)] was 55.0 (12.3) years. The mean of time at onset of RA (SD) was 11.2 (9.1) years. A total of $311(49.8 \%)$ patients had FM; of them $91.6 \%$ were women and the mean age (SD) was 54.5 (12.2) years. In the univariate analysis RA patients with FM were more likely to be older and smokers, have seropositive RA, higher body mass index and longer time at onset of RA, show worse functional status by $\mathrm{HAQ}$ and more radiographic progression, present more extra-articular and Sicca manifestations, exhibit increased demand of hip and knee arthroplasty, also reveal a higher frequency of comorbidities including depression, osteoporosis and type 2 diabetes mellitus, besides to use a greater number of disease-modifying anti-rheumatic drugs (DMARDs), more biologic agents and higher doses of corticosteroids. Also, $\mathrm{CCl}$ was higher in RA patients with FM. Nevertheless, no differences were found for RA disease activity in both groups. In multivariate analysis, higher score of $\mathrm{CCl}(\mathrm{OR} 1.21,95 \% \mathrm{Cl} 1.01-1.44$, $\mathrm{p}=0.037$ ) remained significant in RA patients with $\mathrm{FM}$. 